\title{
ORGANIZAÇÕES INTERNACIONAIS E ONGS NO SISTEMA DE REDES DA SOCIEDADE GLOBAL COMPLEXA
}

\author{
Ingrid Nayara Nogueira Bastos dos Santos \\ Aluna do Curso de Direito da FA7. Relato sob a orientação \\ do prof. Me. Ramon Negócio (FA7) \\ ingridnnbs@gmail.com
}

\section{INTRODUÇÃO}

O estudo ora exposto tem como principal objetivo compreender como se dão as relações de entrelaçamento e influência entre os atores da sociedade global complexa, mais especificamente organizações internacionais e ONGs, e como seus padrões técnicos podem ser decisivos para que suas deliberações tenham força vinculante, ou, pelo menos, fortemente persuasivas, para a tomada de decisões no âmbito jurídico e político dos Estados. A metodologia de pesquisa utilizada foi a de análise de produções acadêmicas sobre a matéria e a observação da dinâmica de relações de influência no cenário internacional.

\section{Teoria dos Sistemas e Complexidade}

O referencial teórico adotado no presente trabalho colhe lastro nos estudos sociológicos de Niklas Luhmann, a partir do qual é possível ter uma compreensão acerca do que seria sociedade, composta por subsistemas e seus respectivos ambientes e, consequentemente, o que caracterizaria, nela, a complexidade. Referida análise guarda especial relevância para a pesquisa ora realizada em razão dos pressupostos que serão aqui adotados, quais sejam, noção de sociedade global e complexa.

Nesse contexto, a partir da utilização da noção de "mundo" como a mais alta referência possível, no sentido que abrange todos os sistemas e ambientes, sendo a unidade entre eles e funcionando como sede para tudo o que acontece ou é plausível de ocorrer, Luhmann propõe a complexidade como uma totalidade de acontecimentos e, no mínimo, duas circunstâncias possíveis, de modo que existiria uma pluralidade de como seria construída a realidade, que seria um produto de somas de ocorrências que acontecem de determinada maneira, mas que poderiam ter sido diferentes.

Dessa maneira, os subsistemas sociais seriam formados não apenas de seus respectivos elementos especializados de comunicação, mas também de conexões relacionais entre aludidos componentes cominicativos, tanto internamente como com outros subsistemas (ou seja, ocorre uma troca de informações, num fluxo contínuo e plurilateral, entre os componentes comunicativos do próprio subsistema e os constituíntes comunicativos de seu ambiente, que brange outros subsistemas). 
Portanti tem-se que há um crescimento de relações, de interações e troca de informaçõs entre os componetes de cada sistema, sendo esse aumento proporcional ao aumento de número do possibilidades da própria realidade, e, consequentemente, todo esse processo encadeado ensejará o aumento da própria complexidade, pois cada vez mais surgirão novas informações, dentro e fora do sistema, que se inter-relacionarão e gerarão mais informações, o que aumentará a complexidade do meio a partir do número crescente de possibilidades comunicativas e informacionais que podem se concretizar na realidade social. (BAETA NEVES; MONTEIRO NEVES, 2006) ${ }^{1}$.

\section{Sociedade Global e Redes}

A sociedade global hodierna, dotada de alta complexidade, nos termos anteriormente explicitados, está imersa também em estruturas de redes, no sentido de estruturas sociais abertas nas quais as informações fluem a partir de operações de tecnologia de comunicação. Essas redes são compostas por sistemas de nós interligados, que são o aspecto formal da linguagem, a partir dos quais a rede tem pontos de interseção, de modo que a evolução das redes se dá com o acréscimo ou remoção de nós, de acordo com as alterações que se fazem necessárias para que os programas consigam atingir os objetivos de performance desse trabalho em rede.

Aludidos programas, cuja elaboração social ocorre fora do âmbito das redes em si, funcionarão como diretrizes compulsórias para estas no momento em que forem inscritos na lógica dessas redes, que irão acrescentar, remover ou alterar nós até que sobrevenha um novo programa que modifique os códigos que regem esse sistema operacional.

Nesse diapasão, a área da comunicação é transformada, havendo a comunicação interpessoal, que é constituída no âmbito privado, por atores de interação, e a comunicação mediática, que são os relacionamentos entre instituições e organizações da sociedade e as pessoas que os formam, considerados não como indivíduos, mas como receptores coletivos de informação, sendo por essa razão que a comunicação é essencial na formação de consciência da coletividade e, consequentemente, na tomada das decisões políticas e jurídicas. Essa difusão da sociedade em rede, portanto, enseja a formação de inúmeras redes horizontais de comunicação, as quais, independentes da mídia e dos governos, configuram a denominada massa autocomandada (CASTELLS, 2005) ${ }^{2}$.

\section{Organizações Internacionais, Ongs e Sua Influência Nas Decisões Políticas e Jurídicas}

Nesse contexto de sociedade complexa composta de redes, tem-se que as organizações internacionais, como membros do direito internacional privado, funcionam como campo para a elaboração de tratados internacionais sobre diversas matérias, e produzem atos unilaterais de regulamentação internacional, que podem ser classificados como atos heteronormativos, visto que se dirigem a indivíduos independentes em relação à organização internacional.

Dessa maneira, tais organizações podem ser dotadas de um verdadeiro poder regulamentar externo, de modo que, além de seus atos unilaterais terem o potencial de influenciar na formação de um costume ou mesmo em uma decisão judicial, a partir do reconhecimento de um princípio geral do direito, ainda podem proferir disposições de efeito regulamentar ou decisões

1 BAETA NEVES, Eckert; MONTEIRO NEVES, Fabrício. O que há de complexo no mundo complexo? Niklas Luhmann e a Teoria dos Sistemas Sociais. CLARISSA. Sociologias, Porto Alegre, ano 8, nº 15, jan/jun 2006, p. $182-$

2 CASTELLS, Manuel. A Sociedade em Rede: do Conhecimento à Política. Conferência Promovida pelo Presidente da República. 4 e 5 de março de 2005 | Centro Cultural de Belém. Organizado por Manuel Castells e Gustavo Cardoso. p. 16-29. 
de alcance geral, que acabam se tornando obrigatórias (no sentido de que não há necessidade de incorporação, sendo os efeitos automáticos) para os Estados que as integram, mesmo havendo a possibilidade de rejeição total ou de reservas por parte destes, o que demonstra o mínimo de discricionariedade que lhes foi conservado.

Essa obrigatoriedade se dá, principalmente, em razão dos padrões técnicos adotados como paradigmas de segurança, por causa da especialidade científica com a qual são elaborados alguns desses atos unilaterais, de modo que, quanto maior o grau de cientificidade, teoricamente, do ato unilateral, maior seria sua força persuasiva e vinculante. O problema é quando são formadas verdadeiras indústrias científicas, como no caso da produção de medicamentos, em que a saúde, como direito, fica à mercê de deliberações no âmbito negocial e, em tese, científico, sendo que a ciência é construída a partir de divergências (VENTURA, 2013) . $^{3}$

Por sua vez, as Organizações Não Governamentais, especificamente, foram criadas visando descrever e construir um relacionamento específico entre organizações civis e o processo intergovernamental. No entanto, o termo "ONG" tem sido usado para qualquer organização que não seja pública, que não tenha vínculo com o governo, quando seria melhor denominá-las de organizações da sociedade civil, podendo esta ser entendida como uma esfera de interação social entre grupos sociais e o Estado, caracterizada pela cooperação comunitária, estruturas de associação voluntária e trabalhos em rede (networks) de comunicação pública.

Essas organizações da sociedade civil, ou, como referidas de modo mais geral, as ONGs, trazem à pauta internacional problemas e discussões específicos relacionados aos grupos que representam, como o International Rescue Committee, que oferece assistência para refugiados de guerra e vítimas de catástrofes.

Na sociedade global moderna, as organizações da sociedade civil assumem um papel ainda mais importante na influência de agentes e de instituições determinantes no cenário global. O trabalho em rede (network) realizado por elas têm demonstrado efeitos significativos, principalmente na mobilização da mídia internacional, o que acaba por gerar ingerências nas decisões políticas e jurídicas tomadas pelos Estados (KRUT, 1997)4.

\section{Considerações Finais}

A partir da pesquisa realizada, é possível depreender que, em um contexto de sociedade global, complexa em todos os seus aspectos, com pluralidades de atores e elementos de comunicação, está imbuída de estruturas de redes (network) dentro das quais existem pontos de “nós", que são pontos de interseção dessa comunicação fluídica. Nesse diapasão, as organizações internacionais e as ONG's atuam como agentes nessa comunicação horizontalizada, prescindindo de intermediadores midiáticos ou governamentais para que suas informações tenham força influenciadora determinante. Isso ocorreria, principalmente, em razão da sensação de segurança proporcionada pelos padrões técnicos adotados por tais entes, de modo que a ciência acabaria sendo vinculante quando da tomada de decisões políticas e jurídicas.

Ao final da pesquisa, espera-se entender acerca de como ocorrem essas relações de influências decisivas entre esses agentes do cenário internacional em um âmbito de redes, além de averiguar o potencial persuasivo e vinculativo dos padrões técnicos.

3 VENTURA, Deisy. Direito e saúde global - O caso da pandemia de gripe A (H1N1). São Paulo: Outras Expressões; Dobra Editorial, 2013. p. 137-142; 251-259.

4 KRUT, Riva. Globalization and Civil Society: NGO Influence in International Decision-Making. (United Nations Research Institute for Social Development Geneva 1997). p. 11, 49-50. 



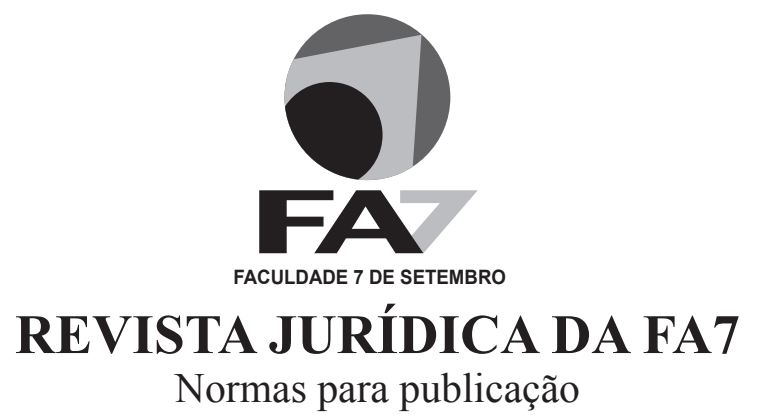

1. A REVISTA JURÍDICA DA FA7 propõe-se a publicar textos jurídicos, cujos originais serão avaliados por pares, no sistema de double blind review.

a) Os textos publicados expressam a opinião de seus autores e são de sua exclusiva responsabilidade.

b) Os textos deverão caracterizar-se pelo uso adequado do vernáculo, pela concisão, pela precisão e pela clareza.

c) Será aceita apenas uma versão do texto. O articulista deve realizar toda revisão que julgar necessária, inclusive metodológica, ortográfica e gramatical antes da submissão.

2. O editor informará aos autores se seus textos submetidos para publicação foram ou não aprovados.

a) Pequenas alterações no texto serão feitas pelo Conselho Editorial.

b) Alterações substanciais serão solicitadas pelo editor ao autor, que terá sete dias úteis, a contar da data do recebimento da solicitação, para fazê-las. Caso o autor não as faça, seu texto será desconsiderado para publicação.

c) Não serão aceitas modificações após o envio dos textos para a gráfica.

3. Os textos submetidos para publicação deverão ser enviados à coordenação do curso de Direito da FA7, diretamente para rjurfa7@,fa7.edu.br, conforme abaixo:

I. em total obediência às normas da Associação Brasileira de Normas Técnicas (ABNT) e do Manual de Formatação de Monografia Jurídica, do Curso de Direito da FA7, que se encontra disponível no sítio eletrônico da FA7;

II. gravados em MS Word (.doc) ou BrOffice (.odt), em papel tamanho A4, fonte Arial corpo 12 para texto principal, espaço 1,5 entre linhas e entre parágrafos, folhas numeradas;

III. nas citações diretas longas, em fonte Arial tamanho 11, espaçamento simples, recuo do texto de $4 \mathrm{~cm}$;

IV. as notas de rodapé, em fonte Arial tamanho 11, devem ter caráter meramente explicativo;

V. citações diretas e/ou indiretas no sistema autor-data, no próprio corpo do texto. Exemplos:

Antes da citação: "De acordo com Francisco Rezek (2011, p. 72):..."; ou

Depois da citação: “... (BEVILÁQUA, 1912, p. 39).”

VI.referências em conformidade com a norma ABNT NBR 6023/2002. 
4. Os textos submetidos para publicação deverão ser classificados conforme abaixo, obedecendo à respectiva extensão:

a) Estudos teóricos/ensaios - análises de temas e questões fundamentadas teoricamente, levando questionamentos de modos de pensar o Direito e a novas elaborações (extensão em torno de 6.000 palavras). Neste caso, é necessário conter estes elementos pré-textuais: título em português e inglês; nome e breve identificação do autor; sumário; resumo e abstract (destacando finalidades, metodologia, resultados e conclusões do documento, com extensão de 100 a 250 palavras cada, mais três a cinco palavras-chave, e respectivas keywords). A parte textual deverá ser dividida em: introdução, desenvolvimento (podendo ser subdividido) e conclusão. Como elementos pós-textuais: referências e, se houver, apêndices e/ou anexos.

b) Relatos de pesquisa - investigações baseadas em dados empíricos, recorrendo a metodologia quantitativa e/ou qualitativa. Neste caso, é necessário conter, no mínimo, introdução, metodologia, resultados e discussão (extensão em torno 4.000 palavras);

c) Comunicações - relatos breves de pesquisas ou trabalhos apresentados em reuniões científicas/eventos culturais (extensão em torno de 3.000 palavras);

d) Ressonâncias - resenhas, comentários complementares e réplicas a textos publicados (extensão em torno de 3.000 palavras);

e) Resumos - de tese, dissertação ou monografia devidamente aprovada e recomendada unanimemente por banca examinadora de instituição de ensino superior, com identificação do professor orientador (extensão: 200 a 600 palavras).

5. Os textos enviados deverão ser acompanhados de termo de declaração preenchido e firmado pelo autor, cedendo gratuitamente seus direitos autorais para publicação e confirmando que já foi submetido a revisor qualificado. O referido termo encontra-se no sítio eletrônico da FA7.

6. Permite-se a reprodução de textos publicados na revista, desde que seja citada a fonte.

Fortaleza, abril de 2013

$\mathrm{O}$ editor. 